\title{
KAP STUDY
}

\section{Volunteering Activity as A Source of Life Satisfaction among Medical and Dental Students of Karachi, Pakistan}

\author{
Shaista Emad 1,2, Faiza Nasir2, Ayesha Akhlaq², Syed Raheel Pasha'2, Mohd Jahanzaib Noor', Rubina Ghani \\ 'Department of Biochemistry, Sohail University, 2Jinnah Medical and Dental College Karachi, Pakistan.
}

\begin{abstract}
Background: Community Service is an integral component of undergraduate medical education. A volunteer is an individual who, without pay, reaches out beyond the confines of their normal responsibilities; freely and willingly contribute in different ways. Volunteering and serving others can help decrease tension, mentally empower volunteers and offer purpose in life. This study aimed to assess the motivation behind volunteering activities among medical students.
\end{abstract}

Methods: A cross sectional study was conducted comprised of a total of 450 students of different private and government sector medical colleges of Karachi, Pakistan. A volunteer functional inventory (VFI) questionnaire was used for the study. Predictability of motivation behind volunteerism was analyzed by student's t-test through SPSS software.

Results: Out of the 450 participants in this study, $286(64 \%)$ of respondents were found to be volunteers and $164(36 \%)$ were non-volunteers, the largest respondents constituting $154(66.7 \%)$ had been volunteering for 1-5 months, $63(14 \%)$ spent time in volunteering for 6-10 months. It was found that $228(50 \%)$ of the students were influenced by their friends to start the act of volunteering. About 72(42\%) of respondents were involved in community volunteering in health and emergency services. The various variables of the motivation (protective factor, value factor, career factor, social factor, understanding factor and enhancement factor) among medical students were determined significant $(p<0.05)$.

Conclusion: Medical students can effectively contribute in the training and healthcare initiatives. To the best of our knowledge, the involvement of healthcare volunteering is beneficial both at a personal and academic level for medical students.

Keywords: Community Service; Depression; Health; Medical Emergencies; Stress.

\author{
Corresponding Author: \\ Dr. Shaista Emad \\ Department of Biochemistry, \\ Sohail University, BMCHS Sharafabad, \\ Karachi, Pakistan. \\ Email: shaista.emad@yahoo.com \\ https://doi.org/10.36283/PJMD10-1/015
}

\section{INTRODUCTION}

Volunteerism is the principle of an individual offering their time, energy, services, knowledge and skills freely for the benefit of other people in the community as a social responsibility rather than for any financial reward'. The developing nations are still struggling in the field of volunteerism and it is not among the common activities in Pakistan. In Pakistan, the volunteer activity is said to be only $16 \%$ ranking and it is 78th in the world ${ }^{2}$. There is a lack of awareness about formal volunteering among students and the public. The concept of formal voluntary work is any unconditional donation or effort to organizations, practices ${ }^{3}$. Knowledge and understanding of volunteerism influence people to participate in volunteering programs despite the country's economic conditions ${ }^{2}$.

The health care profession is emotionally demand- 
ing as compared to other fields ${ }^{4}$. Medical students experience stress, depression and this is one of the reason that they participate in different activities to burnout stress ${ }^{1,5}$. The medical students commonly practice volunteering activity and they work individually or in groups and contribute their time, skills, energy, resources etc. Studies reported various fields of voluntary work as volunteers to offer their services in volunteering as per their field of interest ${ }^{6}$. Volunteer organizations are categorized as political, environmental, recreational, cultural, human services, educational and other ${ }^{7}$. Volunteering is a practice that may seem quite self-sacrificing, but it serves the volunteer for several purposes ${ }^{8}$.

Volunteering offers vital assistance to people in need, valuable causes and society, but the rewards for the volunteer become even significantly higher 9.10 . Volunteering and serving others can help decrease tension, combat sadness; mentally empower volunteers and offer meaning and purpose in life" ${ }^{11}$. Voluntary work may not only help the vulnerable, but also the volunteer ${ }^{12}$. There are six main functions served by volunteering services including values, understanding, social, career, enhancement and protective ${ }^{13}$. The values function works on those points that show how much we value the people in need.

The understanding function relates to the knowledge and competencies that a volunteer may have. The social function deals with the relationship between a volunteer and the society ${ }^{14}$. The career function is represented as the volunteers get to experience many things and it will help them in their profession. The enhancement function relates to personal growth. The last function is protection, which relates to the volunteers' problems. By getting involved in volunteering, they forget their troubles and protect themselves from negativity ${ }^{15}$. The Volunteer Function Inventory (VFI) was created to determine the degree to which each of these functions is served by volunteering ${ }^{16}$. This study aimed to provide insights into how medical students are involved in volunteering and how the act of volunteering helps to foster relationships that are more positive with patients.

\section{METHODS}

A cross sectional study was conducted comprising of a total of 450 students (male and female) of different private and government sector medical colleges of Karachi, Pakistan. The medical institutes, which were included in the study, are Dow University of Health Sciences, Liaquat National Medical and Dental College, Liaquat College of Medicine and Dentistry, Karachi Medical and Dental College,
Jinnah Sind Medical University, Sir Syed College of Medical Sciences for Girls and Dow International Medical. Only MBBS and BDS students participated in the study. Students from other disciplines were excluded.

Ethical approval was obtained from the "Ethical Review Committee (ERC), Jinnah Medical and Dental College, (ERC.No.06-B19/30-11-2018). Volunteer functional inventory (VFI) scale that followed the international guidelines for volunteerism including comparability, feasibility, cost-effectiveness, efficiency and reliability was used for the study. VFI scale of volunteerism comprised of thirty items that measure motivational level for volunteering services. Participants were asked to answer each item on a scale of 7 points that ranges from 1 to 7 (strongly disagree/strongly agree). Volunteer functional inventory (VFI) questionnaire measures protective, value, career, social, enhancement and understanding functions ${ }^{16}$. Sociodemographic characteristics such as gender, age, education (MBBS or BDS), socioeconomic status (upper, middle or lower), marital status (single, married or engaged) and occupation (employed or unemployed) of each of the participant were also determined in the study. Questionnaire form was distributed among medical students of various medical colleges of Karachi. Formal approval was taken from each of the medical institutes participated in the study. The purpose of the study was described to each participant. Instructions and confidentiality issues were also described. Descriptive statistics of the measures were examined, as well as predictability of motivation behind volunteerism was analyzed by student's t-test through SPSS software version 20.0.

\section{RESULTS}

The study comprised 450 participants both male and female. The female participants constituted $65.8 \%(n=296)$ of the entire sample population, whereas male respondents were $34.2 \%(n=154)$ of the sample. The age group between 17-30 years of the respondents was included in the study. The maximum number of participants involved in the volunteering activity was 21 years old and it was found that $286(64 \%)$ of respondents were found to be volunteers and $164(36 \%)$ were non-volunteers (Table 1). Time was the major contributing factor in our study and the maximum number of respondents contributed their time for volunteering activity. However, it was also observed that majority of the respondent involved in volunteerism for the enhancement of their skills that enables them to critical thinking, communication, creativity, and problem solving. 
Table 1: Demographic characteristics of the study participants.

\begin{tabular}{|c|c|c|c|}
\hline Variables & Category & Frequency (n) & Percent (\%) \\
\hline \multirow[b]{2}{*}{ Gender } & Male & 154 & 34.2 \\
\hline & Female & 296 & 65.8 \\
\hline \multirow{3}{*}{ Marital Status } & Single & 408 & 90.7 \\
\hline & Married & 17 & 3.8 \\
\hline & Engaged & 25 & 5.6 \\
\hline \multirow{3}{*}{ Age (years) } & $17-20$ & 179 & 40 \\
\hline & $21-24$ & 258 & 57 \\
\hline & $25-30$ & 13 & 3 \\
\hline \multirow[t]{2}{*}{ Education } & MBBS & 306 & 68 \\
\hline & BDS & 144 & 32 \\
\hline \multirow{3}{*}{ Socioeconomic Status } & Upper & 57 & 12.7 \\
\hline & Middle & 380 & 84.4 \\
\hline & Lower & 13 & 2.9 \\
\hline Volunteer & - & 286 & 64 \\
\hline Non Volunteer & - & 164 & 36 \\
\hline \multirow{6}{*}{ Duration of Volunteering } & $1-5$ months & 154 & 66.7 \\
\hline & 6-10 months & 63 & 14 \\
\hline & $11-15$ months & 23 & 5 \\
\hline & $16-20$ months & 18 & 4 \\
\hline & $21-25$ months & 10 & 2.22 \\
\hline & over 25 months & 04 & 0.88 \\
\hline
\end{tabular}

According to the findings, the largest respondents constituting $154(66.7 \%)$ had been volunteering for 1-5 months and the maximum time engaged in volunteering services among the $n=176$ respondents was 1-10 hours. The largest volunteer respon- dents constituted $228(49.4 \%)$ were influenced to start volunteering by their friends, whereas $72(42.0 \%)$ of the respondents worked as a community volunteer in health and emergency services (Figure 1a, 1b). 


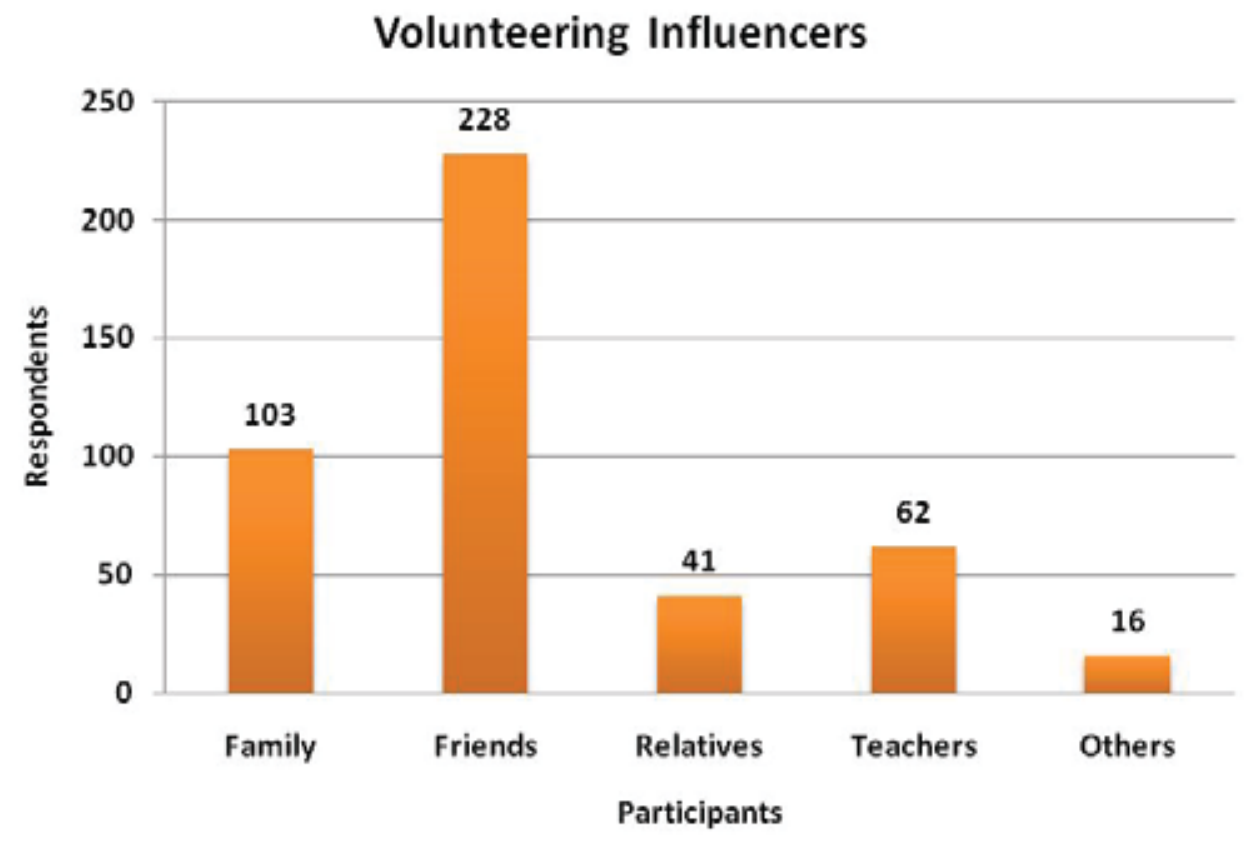

(a)

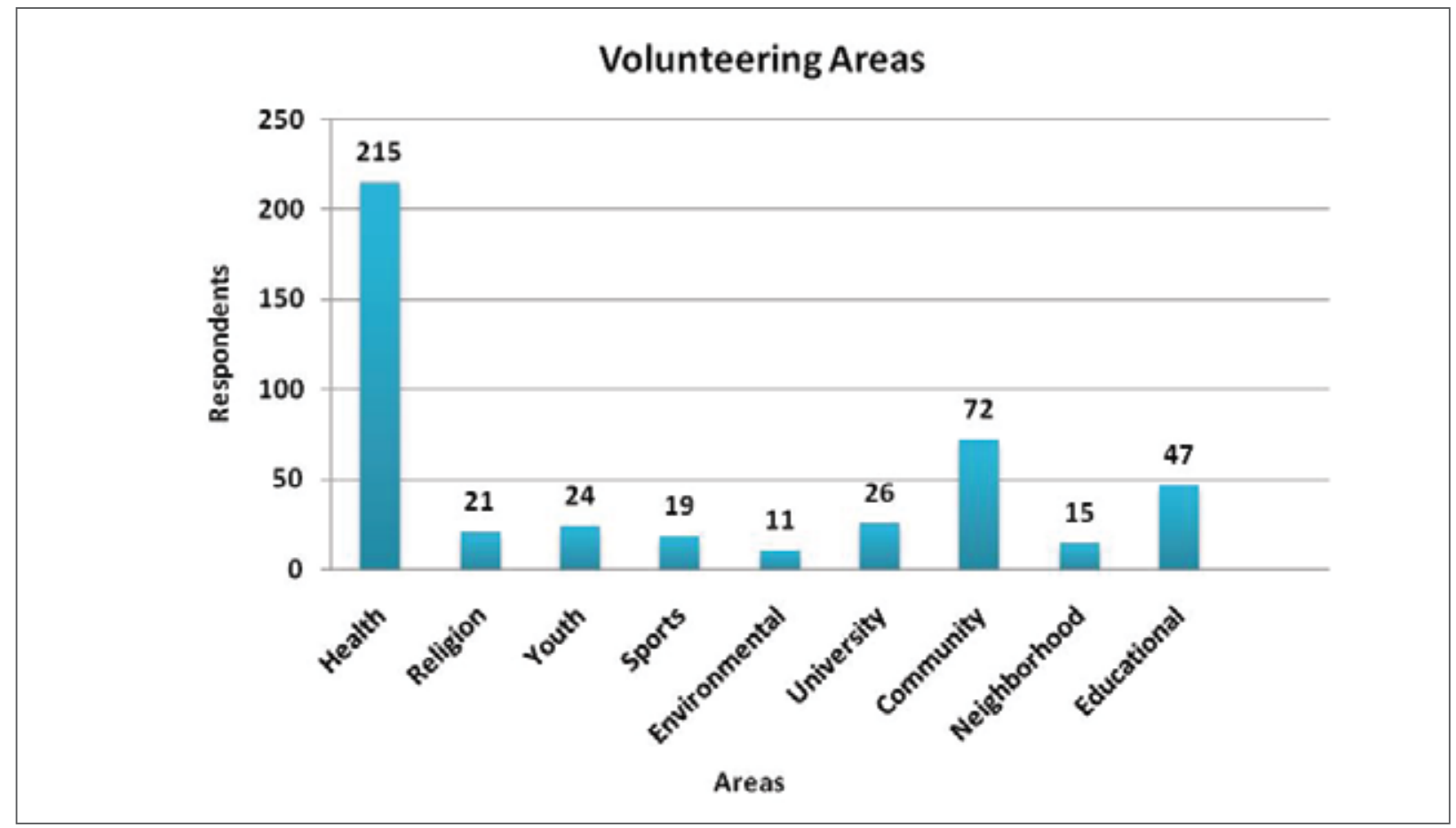

(b)

Figure 1: (a) sources that influence volunteering and (b) areas of volunteering. 
The results of the present study showed a significant difference in the motivation, underlying factors, time, and areas and on the contributing factors. The six factors of motivation that lay the foundation for voluntary work includes protective factor, value factor, career factor, social factor, understanding factor and enhancement factor were found to be significant among the participants who participated in the study (Table 2).

Table 2: Variables of the motivation behind volunteerism among medical and dental students of Karachi.

\begin{tabular}{|l|c|c|c|}
\hline \multicolumn{1}{|c|}{ Variables } & Mean \pm SD & t-test & $p$-Value \\
\hline Protective factor & $22.89 \pm 7.49$ & -1.263 & 0.053 \\
\hline Value factor & $25.92 \pm 7.46$ & -2.872 & 0.004 \\
\hline Career factor & $28.91 \pm 7.25$ & -.948 & 0.036 \\
\hline Social factor & $23.43 \pm 7.04$ & -1.403 & 0.017 \\
\hline Understanding factor & $30.51 \pm 7.99$ & -2.236 & $<0.01$ \\
\hline Enhancement factor & $24.58 \pm 7.33$ & -1.401 & 0.005 \\
\hline
\end{tabular}

\section{DISCUSSION}

Medicine is a service-oriented profession that involves professional approaches and a sense of responsiveness and caring. Volunteering offers vital help to people in need, worthwhile causes, and the community, but the benefits can be even greater for the volunteer. This study aimed to examine patterns and attitudes toward volunteering activity among medical students in different institutes of Karachi, Pakistan. We found a high level of volunteerism among medical students who participated in the study. It is generally observed that young people volunteer for different reasons and benefits than older people pr,18. $^{17}$.

There is always some motivation behind the act of volunteering. The foremost reason for young people is the opportunity to achieve work-related knowledge, skills, and qualifications that can help them in their education and careers $^{19}$. Medical field is a service related job, which needs professional attitudes, the wisdom of sympathy and cares for the patients'. Volunteering activity decreases mortality, improves self-rated health, mental health, life satisfaction, the ability to carry out activities of daily living without functional impairment, social support and interaction, healthy behaviors and the ability to cope with one's illness 5,15 . It is generally observed that health care professionals from developed countries are regular volunteers ${ }^{20}$. Volunteering brings outcomes, or impacts, for students, communities, education institutions, and employers ${ }^{10,21}$.

This study represents one of the first attempts to assess the sociodemographic characteristics of volunteerism activity among medical students of Karachi, Pakistan. We collected the data from 450 medical students in different medical colleges out of which 296 were female and 154 were male. In our study, we have attempted to cover all aspects of voluntary work to provide a detailed analysis of voluntary activities. The different categories in the areas of volunteering include health and emergency services, religious organizations, youth (mentor, tutor, coach, and counselor), sports or cultural activities, environmental, university clubs or organizations, community activities, neighborhood, educational and miscellaneous. The age of the respondents was between 18-26 years and the mean age was 20 years. Younger volunteers appear to be more motivated morally ${ }^{15}$. There is accelerated motivation among youth and they love the idea of helping the people in need ${ }^{22}$. Our results suggested that the maximum number of students had been volunteering for 1-5 months and 1-10 hours in the respective time. Medical students usually get semester break, which shows that they must be utilizing this time for some volunteer work. Friends play a major role in our life. Our friends influence us more easily. Volunteering is teamwork and friends together will make a better team. Friends are interlinked, which means interconnecting their opinions, emotions and attitudes are interrelated ${ }^{23}$.

According to our study, friends were found to be a motivating factor for volunteering individuals. Medical students are more in contact with the patients and in one-way or another; they give their maximum time in health and emergency services ${ }^{24}$. Volunteering in health and emergency services is easy for them. Volunteering activities can include donation drives for patients who cannot afford their treatment, etc ${ }^{25}$. Our participants were found to be more interested in health and emergency services. This shows their contribution to direct patient care is likely to have substantial impacts on the patient's health and well-being. Time is also a major contributing factor in volunteering activity ${ }^{24}$. In our study 117 of the respondents contributed their time for volunteering activity. Spending time with patients, listen to those who have no one to talk or play with children who are physically or mentally unwell. Volunteering is not just about giving. We do not just give our services but also get so much in return in a bilateral process ${ }^{26}$.

Volunteering provides chances for college students to develop their social media platforms to improve their curricula and increase their personality-confidence through an exchange experience ${ }^{26}$. Volunteering requires skills, time, money and above all passion and courage. Some factors keep a volunteer motivated. Factors include support from family and friends, their profession and the most important factor in their field. One of the biggest motivators for volunteering is the simple pleasure of contributing something valuable to society, wanting to feel supportive ${ }^{27,28}$. In the present study motivation 
factors that lay, the foundation for voluntary work including protective factor, value factor, career factor, social factor, understanding factor and enhancement factor were found to be significant. Findings of the present study suggest a more promising approach to promoting future involvement of students in volunteerism and to develop important values like humanitarianism, skills, the goal of gaining career-related experience, social relationships and to address personal problems.

\section{CONCLUSION}

Public health policy makers are motivated to encourage healthcare volunteering among the medical and dental students. They should promote a culture of volunteerism among students and explore potential mediators that link the relationship between volunteering and healthcare benefits.

\section{ACKNOWLEDGEMENTS}

We are thankful to the participants of government and private medical universities of Karachi for giving us their time and consent. We are also grateful to Jinnah Medical and Dental College for providing us facilities for this study.

\section{CONFLICT OF INTEREST}

The authors declare no conflict of interest.

\section{ETHICS APPROVAL}

Ethical approval was obtained from the Ethical Review Committee (ERC) of Jinnah Medical and Dental College, Karachi, Pakistan.

\section{PARTICIPANTS CONSENT}

Verbal and written informed consent was obtained from all participants.

\section{AUTHOR'S CONTRIBUTION}

FN and AA did sample collection and wrote the manuscript. SRP and MJN did statistical analysis SE conceived the idea and overall supervised the project and finalized the manuscript. RG helped in sampling and designing of the project.

\section{REFERENCES}

1. Yeung JW, Zhang Z, Kim TY. Volunteering and health benefits in general adults: Cumulative effects and forms. BMC Public Health. 2018;18(1):1-8.

2. Mattiullah Butt BH, Kamran Ahmed Soomro. Volunteering activities in developing countries: A study of youth participation in Pakistan. Eur J Business Manag. 2015;7(13):317-326.
3. Stukas AA, Hoye R, Nicholson M, Brown KM, Aisbett L. Motivations to volunteer and their associations with volunteers' well-being. Nonprofit Volunt Sect Q. 2016;45(1):112-132.

4. Malby R, Boyle D, Crilly T. Can Volunteering Help Create Better Health and Care. An evidence review [Internet] London South Bank University, 2017 [cited 2020 Sep 16]. Available from https://openresearch.Isbu.ac.uk/download/

5. Atchley R, Baxter S, Blanchard J, Brady K, Comfort W, Egbert A. Working with seniors: Health, financial and social issues. Denver, CO: SCSA. 2009. p.10.

6. Francis JE. The functions and norms that drive university student volunteering. Int J Nonprofit Volunt Sect Mark. 2011;16(1):1-12.

7. Gage III RL, Thapa B. Volunteer motivations and constraints among college students: Analysis of the volunteer function inventory and leisure constraints models. Nonprofit Volunt Sect Q. 2012;41 (3): 405-430. 8. Smith DH. A survey of voluntaristics: Research on the growth of the global, interdisciplinary, socio-behavioral science field and emergent inter-discipline. Voluntaristics Rev. 2016;1 (2):1-81.

9. Brauchli R., Peeters, MC, van Steenbergen, EF., Wehner T, Hämmig $O$. The work-home interface: Linking work-related wellbeing and volunteer work.J Community Appl Soc Psychol, 2017; 27(1), 50-64.

10. Detollenaere J, Willems S, Baert S. Volunteering, income and health. PLoS One. 2017;12(3):e017 3139:1-11.

11. Salt E, Crofford LJ, Segerstrom S. The mediating and moderating effect of volunteering on pain and depression, life purpose, well-being, and physical activity. Pain Manag Nurs. 2017;18(4):243-249.

12. AI Saraidi AS, Awofeso N, Dolan TC. Volunteering in the United Arab Emirates' health system-motivations and challenges. Health. 2020;12(4):334-352.

13. Chacón F, Gutiérrez $G$, Sauto $V$, Vecina $M L$, Pérez A. Volunteer functions inventory: A systematic review. Psicothema. 2017;29(3):306-316.

14. Baver S, Lim D. Effect of communication practices on volunteer organization identification and retention. Sustain. 2019;1 1(9):1-17.

15. Klug G, Toner S, Fabisch K, Priebe S. Characteristics and motivations of volunteers providing one-to-one support for people with mental illness: a survey in Austria. Soc Psychiatry Psychiatr Epidemiol. 2018;53(8):841-847.

16. Chacón F, Gutiérrez G, Sauto V, Vecina ML, Pérez A. Volunteer functions inventory: A systematic review. Psicothema. 2017;29(3):306-316.

17. McDougle LM, Greenspan I, Handy F. Generation green: understanding the motivations and mechanisms influencing young adults' environmental volunteering. Int J Nonprofit Volunt Sect Mark. $2011 ; 16(4): 325-341$.

18. Dean J. Recruiting young volunteers in an area of selective education: A qualitative case study. $\mathrm{Br}$ J Sociol Educ. 2016;37(4):643-661.

19. Same A, McBride H, Liddelow C, Mullan B, Harris C. Motivations for volunteering time with older adults: $A$ 
qualitative study. Plos One. 2020;15(5):1-13.

20. Chatwin J, Ackers L. Volunteering and overseas placements in the NHS: a survey of current activity. BMJ Open. 2016;6(10):1-7.

21. Holdsworth C, Quinn J. The epistemological challenge of higher education student volunteering:reproductive" or "deconstructive volunteering? Antipode. 2012;44(2):386-405.

22. Schroeder T. Investigating barriers to volunteerism in a medical school volunteer patient program: a program development project. Univ Toronto Med J. $2017 ; 94(2): 42-46$.

23. Dury S, De Donder L, De Witte N, Buffel T, Jacquet W, Verté D. To volunteer or not: The influence of individual characteristics, resources, and social factors on the likelihood of volunteering by older adults. Nonprofit Volunt Sect Q. 2015;44(6):1 107-1 128. 24. Tabassum F, Mohan J, Smith P. Association of volunteering with mental well-being: A lifecourse analysis of a national population-based longitudinal study in the UK. BMJ Open. 2016;6(8):1-9.

25. Casiday R, Kinsman E, Fisher C, Bambra C. Volunteering and health: what impact does it really have. London: Volunteer Eng. 2008;9(3):1-3.

26. Aranda M, Zappalà S, Topa G. Motivations for volunteerism, satisfaction, and emotional exhaustion: the moderating effect of volunteers' age. Sustain. 2019;11(16):1-16.

27. Greenfield EA, Marks NF. Continuous participation in voluntary groups as a protective factor for the psychological well-being of adults who develop functional limitations: Evidence from the national survey of families and households. J Gerontol B Psychol Sci Soc Sci. 2007;62(1):S60-S68.

28. Ainsworth, J. Feelings of ownership and volunteering: Examining psychological ownership as a volunteering motivation for nonprofit service organisations. J Retail Consum Serv. 2020;52,e101931. 